\title{
Mediating and Moderating Processes in the Relation between Maltreatment and Psychopathology: Mother-Child Relationship Quality and Emotion Regulation
}

\author{
Lenneke R. A. Alink • Dante Cicchetti • \\ Jungmeen Kim • Fred A. Rogosch
}

Published online: 20 March 2009

(C) The Author(s) 2009. This article is published with open access at Springerlink.com

\begin{abstract}
The present study investigated underlying processes of the effect of maltreatment on psychopathology (i.e., internalizing and externalizing problems) in a group of 111 maltreated and 110 nonmaltreated 7-10 year-old children $(60 \%$ boys $)$. We tested the moderating and/or mediating roles of emotion regulation and the mother-child relationship quality (pattern of relatedness) using Structural Equation Modeling. Emotion regulation, but not the pattern of relatedness, mediated the relation between maltreatment and psychopathology. This mediation was moderated by the pattern of relatedness: For the group of children with an insecure pattern of relatedness, maltreatment was related to lower levels of emotion regulation, which was predictive of higher levels of internalizing and externalizing symptomatology. In contrast, for the secure relatedness group, there
\end{abstract}

This study is supported by a Rubicon grant from the Netherlands Organisation for Scientific Research (NWO) to Lenneke Alink and grants from the Office of Child Abuse and Neglect and the Spunk Fund, Inc. to Dante Cicchetti.

L. R. A. Alink $(\bowtie)$

Centre for Child and Family Studies, Leiden University,

P.O. Box 9555, 2300 RB, Leiden, The Netherlands

e-mail: alinklra@fsw.leidenuniv.nl

D. Cicchetti

University of Minnesota,

Minneapolis, MN, USA

J. Kim

Virginia Polytechnic Institute and State University,

Blacksburg, VA, USA

F. A. Rogosch

University of Rochester,

Rochester, NY, USA was no mediation by emotion regulation since the impact of maltreatment on emotion regulation was not significant. Implications of the mediating role of emotion regulation and the buffering role of the mother-child relationship quality were discussed.

Keywords Psychopathology · Maltreatment · Attachment . Emotion regulation $\cdot$ Moderated mediation

It has been documented widely that children who have experienced maltreatment are at risk for maladaptation and psychopathology (e.g., Manly et al. 2001; Stouthamer-Loeber et al. 2001; Teisl and Cicchetti 2008). To date, research on the developmental consequences of child maltreatment is shifting from studying what goes wrong towards examining how this development of psychopathology takes place. In line with this changing focus, the current study investigates underlying processes linking the effects of maltreatment to psychopathology. A second important developmental issue pertains to factors that prevent or attenuate maladaptive development despite the presence of significant risk factors. Not all children who have experienced adversity will develop emotional and behavioral problems (Luthar et al. 2000). Investigating these protective factors may help to prevent the development of psychopathology in children at risk.

\section{Maltreatment and Psychopathology}

Maltreatment is one of the most severe risk factors that a child may experience. Maltreated children are in jeopardy of developing different types of behavioral and emotional problems, possibly resulting in serious types of trauma- 
related psychopathology (Cicchetti and Toth 2005). A number of prospective empirical studies have shown that individuals who have experienced maltreatment are at risk for different types of psychopathology. For example, maltreatment assessed in childhood has been demonstrated to be related to later depression (Toth et al. 1992), physical and relational aggression (Teisl and Cicchetti 2008), delinquency (Salzinger et al. 2007), and internalizing and externalizing problems in general (Manly et al. 2001).

\section{Emotion Regulation}

A more proximal risk factor for psychopathology, which may mediate the relation between maltreatment and psychopathology, is an impaired development of emotion regulation. Emotion regulation refers to "the processes by which individuals influence which emotions they have, when they have them, and how they experience and express these emotions" (Gross 1998, pp. 275). When patterns of emotion regulation jeopardize or impair functioning, they may support or become symptoms of psychopathology (Calkins and Fox 2002). Several studies have shown that children with impaired emotion regulation skills are at risk for developing different types of psychopathology. In early childhood, poor emotion regulation in girls, assessed at age 2, predicted membership of a chronic-clinical behavior problem profile between the ages of 2-5 years (Hill et al. 2006). In addition, Suveg and Zeman (2004) showed that 8-12 year old children who met the DSM-IV criteria for anxiety disorders had impaired emotion regulation skills compared to their peers without anxiety disorders.

Most research on the relation between emotion regulation and psychopathology has been conducted on normative samples; however, the studies on emotion regulation that have been carried out on maltreated samples help to explain differences in the quality of emotion regulation development. Since parenting plays an important role in the development of emotion regulation, maltreatment would be a major risk factor for the development of maladaptive patterns of emotion regulation (see Camras et al. 1996). Along these lines, Maughan and Cicchetti (2002) reported that maltreated children showed dysregulated emotion patterns in response to simulated interadult anger as compared to nonmaltreated children. Emotion regulation is related to maltreatment on the one hand and emotional and behavioral problems on the other and may thus very well play a role in the explanation of maladjustment in maltreated children. Indeed, emotion regulation mediates the relation between maltreatment and (reactive) aggression, bullying, and victimization (Shields and Cicchetti 2001; Teisl and Cicchetti 2008)

\section{Quality of the Parent-Child Relationship}

The early development of emotion regulation skills is influenced by the quality of the parent-child relationship in the first year of life (Sroufe 1995; Thompson, 2008). Forming an effective attachment relationship with the primary caregiver is the most salient developmental task in infancy (Sroufe 1979). As opposed to children who are insecurely attached to their mother, securely attached children generally will have confidence in the availability of their mother and rely on her as a source of comfort and protection. This will benefit their abilities to negotiate later developmental tasks adaptively (Sroufe et al. 2005; Thompson 2008). In addition to the organized secure and insecure attachment strategies, some children show a disorganized pattern of attachment. Attachment disorganization reflects a momentary breakdown of an organized attachment strategy and can be considered the most insecure form of attachment (Lyons-Ruth and Jacobvitz 2008). Maltreated children are at considerable risk for the development of insecure and, in particular, disorganized attachment relationships (Cicchetti et al. 2006; Cyr et al. 2009).

A solid body of research suggests that attachment security and disorganization are related to psychopathology. Children who have an insecure or disorganized attachment relationship with their mother are more likely to develop externalizing and internalizing behavior problems and are more at risk for impaired emotion regulation skills (e.g., Van IJzendoorn et al. 1999; Warren et al. 1997). Attachment has been shown to be an important construct in the relation between maltreatment and psychopathology; children who are at risk for developing insecure attachment relationships with their caregivers as a result of maltreatment experiences are prone to develop behavioral and emotional problems (see Cicchetti et al. 1995).

Attachment not only has direct effects on development, it also may serve as a risk or a protective factor in the presence of other risk factors. Previous research has indicated that attachment does indeed moderate the effects of risk factors on child development (e.g., Beeghly and Cicchetti 1994; DeKleyen and Greenberg 2008). Several studies have found that secure attachment may serve as a buffer against the negative consequences of stress (e.g., Ahnert et al. 2004; Gilissen et al. 2008b). In these studies, physiological reactivity levels after a stressor were blunted for children with a secure attachment relationship with their mother compared to insecurely attached children. The moderating role of attachment security needs to be investigated more elaborately, because attachment security may help children develop adaptively in case of high contextual risk.

Although most studies on the effects of attachment have focused on the mother-child relationship in the first years of life, attachment continues to be of importance throughout 
development (Kerns, 2008). When children develop, attachment becomes gradually internalized. That is, children form a mental representation, or working model of their attachment relationships based on actual experiences in the relationship (Kerns 2008). Attachment in middle childhood reflects the degree to which there is open communication between the child and the caregiver, the caregiver is physically available, and the caregiver is responsive to the child's bids for help (Kerns et al. 2000). Similar to the effects of attachment in infancy, this construct of attachment representation in middle childhood is related to the quality of emotion regulation skills, more constructive coping, and positive mood (Gilissen et al. 2008a; Kerns et al. 2007). In addition, maltreated children appear to be more at risk for developing insecure patterns of relationship with their mother (Lynch and Cicchetti 1991), suggesting a possible mediating role of relatedness in the association between maltreatment and psychopathology.

Alternatively, the quality of the mother-child relationship may function as a moderator in the effect of maltreatment on psychopathology. Toth and Cicchetti (1996) found that maltreated and nonmaltreated middle school-aged children with insecure patterns of relatedness (i.e., the child's conception of the relationship) were at risk for depression and impaired social acceptance and that maltreated children with a secure pattern of relatedness with their mother showed less depressed symptomatology than maltreated children with insecure patterns of relatedness, indicating a buffering effect of relationship quality in middle childhood.

In summary, the quality of the relationship with the caregiver may serve at least two different functions regarding the relation between maltreatment and psychopathology. First, an insecure relationship may serve as a mediator linking maltreatment to later psychopathology. Second, a secure relationship may, as a moderator, buffer the negative effects of risk factors, such as maltreatment on psychopathology.

\section{The Current Study}

In the current study we focus on the mechanisms of the effect of maltreatment on the development of emotional and behavioral problems. More specifically, the roles of emotion regulation and the quality of the mother-child relationship are investigated.

The study is guided by the following hypotheses

1. Based on previous studies, we expect that maltreated children would show impaired emotion regulation skills, and higher levels of psychopathology compared to nonmaltreated children.
2. We hypothesize that maltreatment influences psychopathology partially through its effect on emotion regulation.

3. We hypothesize that the relation between maltreatment and psychopathology is (partially) mediated by the quality of the mother-child relationship.

4. We hypothesize that a secure mother-child relationship may buffer the negative effect of maltreatment on emotion regulation and psychopathology.

\section{Method}

Participants

The sample consisted of 111 maltreated (73 boys) and 110 nonmaltreated (59 boys) children who attended a weeklong summer camp for inner-city children. The mean age of these children was 9.05 years (range 7.50-10.42). About half of the sample were African-American (56\%), 17\% were Caucasian, 9\% were Hispanic, and 18\% were biracial or other ethnicity. There were on average 3.30 children in a family (range 1-9) and 34\% of the mothers were married or living together. The socio-economic status (SES) of the participating families was low; $76 \%$ fell into the two lowest socioeconomic strata defined by Hollingshead (1975).

The research was reviewed and approved by the University of Rochester Institutional Review Board (IRB). Parents provided informed consent for their child's participation and for examination of any local Department of Human Services (DHS) records pertaining to the family, and children provided signed assent agreeing to participate. Children in the maltreated group had been identified by the county DHS as having experienced child abuse and/or neglect, indicating that the presence of maltreatment had been confirmed after investigation by responsible authorities. Eligible maltreating families were contacted by a DHS recruitment liaison who explained the study. If parents were interested, their names were released to the project team for recruitment. Families were free to choose whether or not to participate. This resulted in a sample that is representative of the local DHS population. The DHS records were coded according to the maltreatment nosology specified in the Maltreatment Classification System (MCS; Barnett et al. 1993; see below).

The maltreated children were predominantly from low SES families, which is consistent with national demographic characteristics of maltreating families (NIS-3; Sedlack and Broadhurst 1996). Consequently, the nonmaltreated group was comprised of children from families who were eligible for Temporary Assistance for Needy Families (TANF) to ensure a low SES-group that is demographically 
comparable to the maltreated group. These low-income nonmaltreating families were also approached by a DHS recruitment liaison. To verify the absence of maltreatment, DHS record searches were performed. In addition, trained research assistants interviewed mothers of children recruited for the nonmaltreated group using the Maternal Maltreatment Classification Interview (Cicchetti et al. 2003) to confirm a lack of DHS involvement. In the year following camp attendance, record searches were conducted to verify that all available information had been accessed. Only children from families without any history of documented abuse and/or neglect and who had not received preventive services through DHS were retained in the nonmaltreatment group. The number of families who had a history of and/or were currently receiving public assistance did not significantly differ between the maltreated (92\%) and the nonmaltreated group (93\%). There were also no significant differences between maltreated and nonmaltreated children in terms of gender, age, ethnicity, and marital status of the mothers.

\section{Design and Procedure}

Data were collected during 1 week summer camps for inner-city children (see Cicchetti and Manly 1990, for detailed descriptions of camp procedures). At the beginning of the camp week, children were assigned to groups consisting of six to eight same-sex, same-age peers, with about the same number of maltreated and comparison children, led by three counselors each who were unaware of the maltreatment status of the children and the hypotheses of the study. The camp consisted mainly of social activities for the children and no formal counseling took place. Trained research assistants, who also were unaware of maltreatment status and research hypotheses, interviewed the children. After each camp week, the group counselors completed questionnaires and Q-sorts based on their observations of the children across the camp session (approximately $35 \mathrm{~h}$ of observation). Several counselors completed the questionnaires for each child.

\section{Measures}

Maltreatment Classification System The Maltreatment Classification System (MCS; Barnett et al. 1993) was used to assess several aspects of maltreatment the children had experienced. The MCS utilizes Child Protective Services (CPS) records detailing investigations and findings regarding maltreatment occurrences in families. Independent determinations of maltreatment experiences are made by coding all information available on a particular family. Trained research assistants, doctoral students, and clinical psychologists coded the CPS records. The system has been proven to be reliable and valid in classifying maltreatment incidents (see Cicchetti et al. 2009). Based on operational definitions contained in the MCS, different subtypes of maltreatment were distinguished: sexual abuse, physical abuse, neglect, and emotional abuse (for a description, see Cicchetti et al. 2009). Among the maltreated children, 79\% had experienced neglect, $64 \%$ had experienced emotional maltreatment, $39 \%$ had experienced physical abuse, and $11 \%$ had experienced sexual abuse. About half of the maltreated children (51\%) experienced multiple subtypes of abuse. Each child received a primary subtype of maltreatment classification ${ }^{1}$. Because there were no differences among the different subtype groups regarding the other variables used in this study ( $p$ s ranging from $0.20-0.65$ ), the maltreated group as a whole was used in the analyses.

Relatedness Questionnaire This questionnaire (Wellborn and Connell 1987) measures children's perceptions of the emotional quality of their relationships and how close they feel to their relationship partners (see Lynch and Cicchetti 1997). In the current paper, we used the children's quality of relatedness with their mother. The questionnaire consists of two subscales. The emotional quality scale (11 items) consists of items that assess children's specific emotions when they are with their mother (e.g., "When I am with my mother, I feel happy"). The psychological proximity seeking scale (six items) consists of items that assess the degree to which children wish they were psychologically closer to the relationship figure (e.g., "I wish my mother spent more time with me," and "I wish I could talk about more things with my mother"). The items were scored on a 4-point scale (1=not at all true, 4=very true). In the present study, Cronbach's alphas were 0.82 for psychological proximity seeking and 0.84 for emotional quality.

Based on the children's scores on the two subscales, their pattern of relationship with their mother was established (see Lynch and Cicchetti 1997). Specifically, high levels of emotional quality (emotional quality scores $>3.0$ ) and low levels of psychological proximity seeking (scores $\leq$ 1.75) indicated optimal patterns of relatedness. Adequate patterns of relatedness were characterized by average levels of emotional quality and psychological closeness (emotional quality scores $>3.0$; psychological proximity seeking scores between 1.75 and 3.0). These two patterns were indicative of relationship security (Cicchetti et al. 1995); children with secure patterns of relatedness feel (fairly)

\footnotetext{
${ }^{1}$ Children who were sexually abused were classified as sexually abused, regardless of their experience of other subtypes of abuse. Children who were physically but not sexually abused were categorized as physically abused, children who were neglected but not sexually and physically abused were classified as neglected, and children who experienced emotional abuse only were classified as emotionally abused.
} 
positive and secure in their relationships and are moderately to highly satisfied with existing degrees of psychological closeness. In addition, deprived patterns of relationships were indicated by low levels of emotional quality (scores $\leq$ 3.0), and high levels of psychological proximity seeking (scores $>2.5$ ). Low levels of emotional quality (scores $\leq 3.0$ ) and low amounts of psychological proximity seeking (scores $\leq 2.5$ ) indicated disengaged patterns. Finally, confused patterns were characterized by high levels of positive emotion (scores $>3.0$ ) as well as extremely high levels of psychological proximity seeking (scores $\geq 3.0$ ). Deprived, disengaged, and confused patterns of relatedness reflected children's perceptions of different forms of relationship insecurity (Cicchetti et al. 1995). In our sample there were 83 children with a secure pattern of relatedness and 138 with an insecure pattern of relatedness.

Theoretically, children's responses to these scales are viewed as consistent with attachment theory (Connell and Wellborn 1991; Lynch and Cicchetti 1991) and responses to the relatedness scales are related to other variables in a way that is consistent with attachment theory (e.g., Toth and Cicchetti 1996). Additionally, Lynch and Cicchetti (1991) have found that the pattern of relatedness in a maltreated sample and a nonmaltreated sample was similar. In addition, this pattern was demonstrated over a wide range of attachment figures in the maltreated and the nonmaltreated group.

Emotion Regulation Q-scale This scale was derived from the California Child Q-set (CCQ; Block and Block 1980/ 1969). The CCQ consists of 100 descriptions of behavior that are sorted into ipsative personality profiles. Shields and Cicchetti (1997) derived an Emotion Regulation Q-Scale from a criterion sort completed by a panel of expert raters. Emotion regulation was defined in terms of lability, flexibility, and situational responsivity and conceptualized as the capacity to modulate one's emotional arousal such that an optimal level of engagement with one's environment is fostered (Cicchetti et al. 1991). After camp sessions, two different counselors completed the CCQ for each child. Means were computed across raters. From these Q-sorts individual scores on the Emotion Regulation Q-scale were generated. The intraclass correlation (average measures), reflecting the interrater reliability was 0.77 .

Teacher Report Form To assess the children's level of internalizing and externalizing behaviors, the Teacher Report Form (TRF; Achenbach, 1991) was used. Camp counselors indicated whether each child displayed any of the 118 behavioral descriptions on a 3-point scale $(1=n o t$ true, $2=$ somewhat or sometimes true, and $3=$ very true or often true). The TRF consists of two broadband syndromes: Externalizing Problems (based on the narrowband syndromes Aggressive behaviors and Delinquent behaviors) and Internalizing Problems (comprising Anxiety/Depression, Withdrawal, and Somatic complaints). Two counselors rated each child and their scores were averaged to obtain individual scores. Interrater reliabilities (intraclass correlations, average measures) were 0.62 for internalizing and 0.83 for externalizing problems. This difference in intraclass correlations for internalizing and externalizing problems is congruent with the broader literature (Achenbach et al. 1987; Grietens et al. 2004).

\section{Discriminating Emotion Regulation from Externalizing and Internalizing Problems}

The assessments of emotion regulation may overlap with the measurement of internalizing and externalizing behavior. Therefore, two principal components factor analyses using varimax rotation were conducted, one including all internalizing and emotion regulation items, and another including all externalizing and emotion regulation items. Since many previous studies have shown that the TRF internalizing and externalizing scales are valid and can be distinguished from each other (see Achenbach 1995 for an overview; Ivanova et al. 2007), we decided not to enter items of both scales in the same factor analysis. The first analysis included all emotion regulation items and TRF internalizing items. Two factors were extracted and crossloading items were dropped. The emotion regulation factor consisted of seven emotion regulation items and 7 TRF items (factor loadings $>0.40$ and no cross-loadings; see Table 1 for specific items). The TRF items were dropped. The internalizing factor was composed of 15 TRF items reflecting internalizing behavior. In the second principal components analysis, all emotion regulation and externalizing items were entered. The emotion regulation factor consisted of seven emotion regulation items and 2 TRF items. These TRF items were dropped from the scale. The externalizing factor was composed of 15 TRF items reflecting externalizing behavior. Only the five items that loaded on the emotion regulation factor in both analyses were selected for the emotion regulation scale. Cronbach's alphas for these scales were 0.93 for the externalizing scale, 0.87 for the internalizing scale, and 0.75 for the emotion regulation scale. The scales were moderately intercorrelated; the correlation between the externalizing and internalizing scales was 0.26 and the correlations between emotion regulation and externalizing and internalizing problems were -0.44 and -0.41 , respectively.

\section{Analytic plan}

First, we investigated differences between the maltreated and the nonmaltreated groups in emotion regulation and 
Table 1 Items for Emotion Regulation, Internalizing, and Externalizing Scales

\begin{tabular}{|c|c|c|c|c|c|}
\hline \multicolumn{2}{|c|}{ Emotion regulation (using CCQ items) } & \multicolumn{2}{|c|}{ Internalizing problems (using TRF items) } & \multicolumn{2}{|c|}{ Externalizing problems (using TRF items) } \\
\hline 3. & Is warm/responsive & 12. & Complains of loneliness & 7. & Bragging, boasting \\
\hline 9. & Develops genuine and close relationships & 14. & Cries a lot & 16. & $\begin{array}{l}\text { Cruelty, bullying or meanness to } \\
\text { others }\end{array}$ \\
\hline 39. & $\begin{array}{l}\text { Tends to become rigidly repetitive or } \\
\text { immobilized under stress }\end{array}$ & 31. & $\begin{array}{l}\text { Fears s/he might think or do } \\
\text { something bad }\end{array}$ & 24. & Disturbs other pupils \\
\hline 54. & Has rapid shifts in mood; emotionally labile & 32. & Feels s/he has to be perfect & 26. & $\begin{array}{l}\text { Doesn't seem to feel guilty after } \\
\text { misbehaving }\end{array}$ \\
\hline \multirow[t]{11}{*}{91.} & Emotional reactions are inappropriate & 33. & $\begin{array}{l}\text { Feels or complains that no one } \\
\text { loves } \mathrm{him} / \mathrm{her}\end{array}$ & 37. & Gets in many fights \\
\hline & & 34. & Feels others are out to get him/her & 39. & $\begin{array}{l}\text { Hangs around with others who get } \\
\text { in trouble }\end{array}$ \\
\hline & & 35. & Feels worthless or inferior & 43. & Lying or cheating \\
\hline & & 47. & Overconforms to rules & 53. & Talks out of turn \\
\hline & & 50. & Too fearful or anxious & 57. & Physically attacks people \\
\hline & & 52. & Feels too guilty & 74. & Showing off or clowning \\
\hline & & 71. & $\begin{array}{l}\text { Self-conscious or easily } \\
\text { embarrassed }\end{array}$ & 90. & Swearing or obscene language \\
\hline & & 81. & Feels hurt when criticized & 93. & Talks too much \\
\hline & & 106. & Overly anxious to please & 94. & Teases a lot \\
\hline & & 108. & Is afraid of making mistakes & 97. & Threatens people \\
\hline & & 112. & Worrying & 104. & Unusually loud \\
\hline
\end{tabular}

adjustment outcomes using $t$-tests and differences in security using a chi-square test. Second, we tested whether relatedness security and/or emotion regulation mediated the relation between maltreatment and internalizing and externalizing problems using Structural Equation Modeling (SEM). The meditational model specified the direct effects of maltreatment on internalizing and externalizing problems as well as indirect effects of maltreatment that are mediated by security and emotion regulation. Next, we performed an analysis of variance (ANOVA) to test the effects of gender, maltreatment, security, and the interaction between maltreatment and security on the child's levels of emotion regulation. Finally, we tested a moderated mediation model (MacKinnon et al. 2007) to examine whether the hypothesized mediation effects of emotion regulation in the link between maltreatment and behavior problems depends on relatedness security, using SEM. A significant moderated mediation is indicated when the indirect effect of maltreat- ment on the outcomes mediated by emotion regulation varies depending on the level of security. We tested the statistical significance of partial mediators using the Sobel test (MacKinnon et al. 2002).

\section{Results}

Differences between the Maltreated and the Nonmaltreated Groups

Table 2 shows means and standard deviations for the study variables. Maltreated children exhibited significantly higher levels of internalizing symptomatology than nonmaltreated children, $t(206.13)=-2.50, p<0.05$ (unequal variances). With respect to emotion regulation, nonmaltreated children scored higher, $t(212.71)=4.00, p<0.05$ (unequal variances), and the rates of secure relatedness tended to be somewhat

Table 2 Differences Between the Nonmaltreated and Maltreated Groups

\begin{tabular}{lccc}
\hline & Nonmaltreated Mean $(S D)$ & Maltreated Mean $(S D)$ & $t / \chi^{2}$ \\
\hline Emotion regulation & $30.64(5.24)$ & $27.52(6.29)$ & $4.00^{* *}$ \\
Internalizing problems & $1.76(2.43)$ & $2.71(3.17)$ & $-2.50^{*}$ \\
Externalizing problems $^{*}$ & $3.76(4.97)$ & $4.72(4.92)$ & -1.43 \\
Relatedness security $^{\text {a }}$ & $44 \%$ & $32 \%$ & $3.45^{\mathrm{b}}$ \\
\hline
\end{tabular}

${ }^{\mathrm{a}} \chi^{2}$ statistic is reported for Relatedness security; percentages of children with a secure pattern of relatedness are given.

${ }^{\mathrm{b}} p=.06 . * p<.05 . * * p<.01$. 
(although not significantly) higher in nonmaltreated children compared to maltreated children, $\chi^{2}(1, N=221)=3.45$, $p=0.06$. The mean difference of externalizing symptomatology between the maltreated and nonmaltreated groups was not significant, $t(219)=-1.43, p=0.15$.

The Mediating Effects of Relatedness and Emotion Regulation

The fit for the model with both relatedness security and emotion regulation as mediators was mediocre, $\chi^{2}(1)=3.39, p=0.07$, $\mathrm{CFI}=0.98$, RMSEA $=0.10$. The results revealed that emotion regulation was a significant mediator $(B=-2.90, S E=0.77$, $p<0.05$ for maltreatment $\rightarrow$ emotion regulation, $B=-0.34$, $S E=0.05, p<0.05$ for emotion regulation $\rightarrow$ externalizing symptomatology, and $B=-0.18, S E=0.03, p<0.05$ for emotion regulation $\rightarrow$ internalizing symptomatology), but relatedness security was not $(B=-0.11, S E=0.07, p=0.53$ for maltreatment $\rightarrow$ security, $B=-0.39, S E=0.62, p=0.53$ for security $\rightarrow$ externalizing symptomatology, and $B=-0.62, S E=$ $0.37, p=0.09$ for security $\rightarrow$ internalizing symptomatology). Thus we tested only emotion regulation as a mediator in the hypothesized model.

\section{The Moderating Effect of Relatedness}

The main effect of maltreatment status in the ANOVA was significant, $F(1,214)=8.95, p<0.01$, partial $\eta^{2}=0.04$. Consistent with the results from the $t$-tests, maltreated children scored lower on the emotion regulation scale $(M=$ 27.52, $S D=6.29)$ than nonmaltreated children $(M=30.64$, $S D=5.24$ ). The effect of maltreatment was moderated by relatedness: The interaction effect of maltreatment status by relatedness was significant, $F(1,214)=5.01, p<0.05$, partial $\eta^{2}=0.02$. Maltreated children were at risk for impaired emotion regulation, but this risk was buffered by a secure pattern of relatedness with the mother (Fig. 1). The other two-way interactions (gender by maltreatment status, and gender by relatedness) were not significant.

\section{Testing a Moderated Mediation Model}

We conducted a two group SEM comparing secure vs. insecure relatedness groups with respect to the direct effects of maltreatment on behavior problems as well as indirect effects of maltreatment that are mediated by emotion regulation (see Fig. 2). Parameters were simultaneously estimated for two separate covariance matrices (secure vs. insecure relatedness) in the series of hierarchically related (nested) models. More specifically, in the Configural Invariance model, all parameters were freely estimated to test whether the patterns of structural relations, rather than the actual numerical values, are invariant between the two

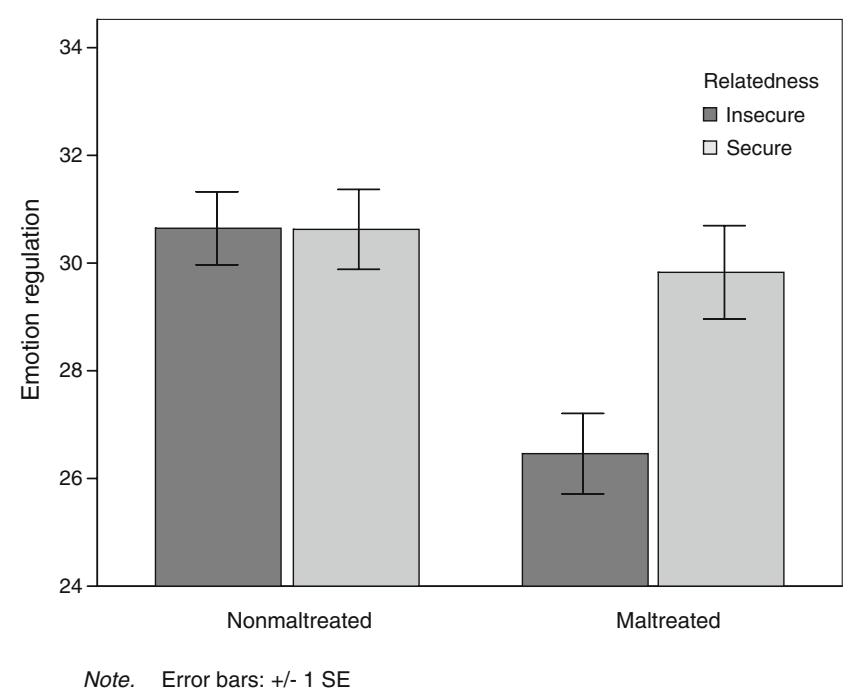

Fig. 1 The interactional effect of maltreatment and relatedness on emotion regulation

groups. This configural invariance model was the least restricted model among the models tested. In the Equal Direct Effect model, equality constraints were imposed to test numeric invariance of the parameters for the direct
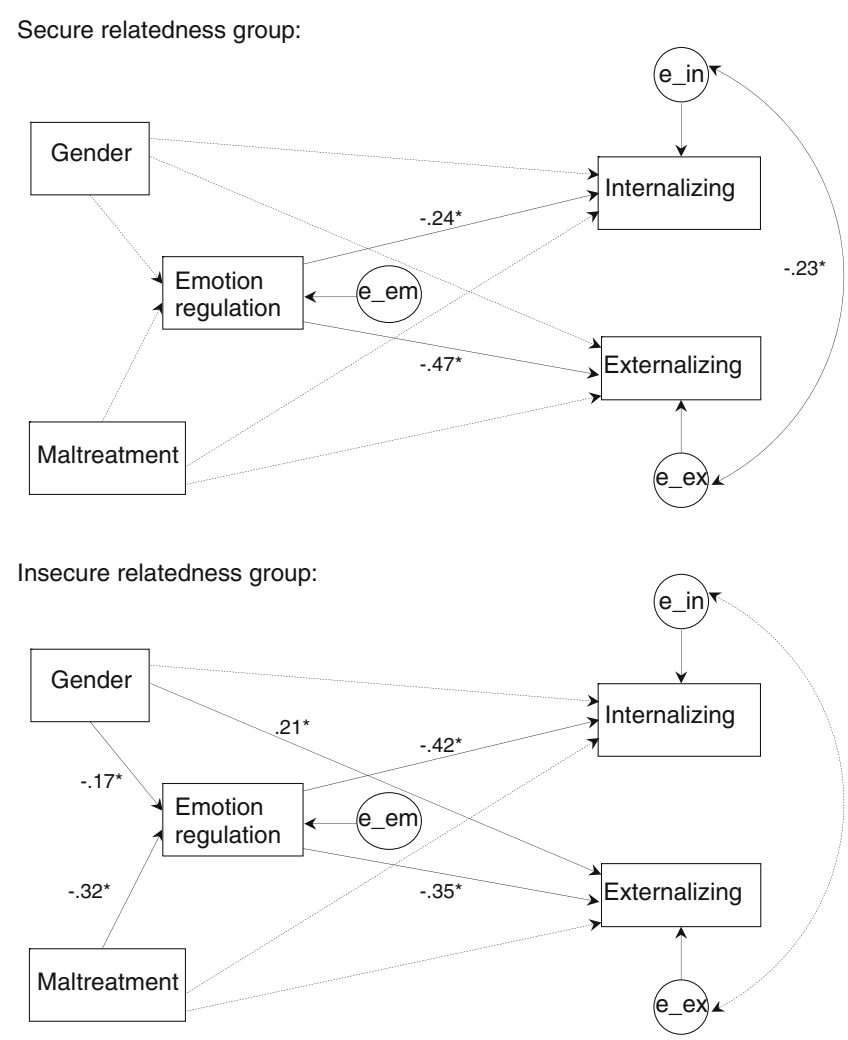

Note. Solid lines represent significant effects (standardized coefficients), dashed lines are nonsignificant.

Fig. 2 Structural equation model for the relation between maltreatment, gender, emotion regulation and internalizing and externalizing problems moderated by relatedness 
effects of maltreatment on child behavioral adjustment between the two relatedness security groups. Finally, in the Equal Indirect Effect model, cross-group equality constraints were imposed between the secure and the insecure relatedness group for the mediational effects of maltreatment on child outcomes via emotion regulation. The adequacy of the equality constraints were tested using nested chi-square difference tests (Bollen, 1989).

The configural invariance model fitted the data relatively well, $\chi^{2}(2)=4.28, p=0.12, \mathrm{CFI}=0.98$, RMSEA $=0.07$. Constraining the regression coefficients for the direct effects of maltreatment to be invariant across the secure and insecure relatedness groups did not lead to a significant deterioration in model fit, $\Delta \chi^{2}=3.70, \Delta \mathrm{df}=2, p=0.16$, suggesting that the direct effects of maltreatment on externalizing and internalizing outcomes did not significantly differ across the two groups. Lastly, the model fit comparison between the Equal Direct Effect model and the Equal Indirect Effect model indicated that the Equal Direct Effect model was a best-fitting model compared to the Equal Indirect Effect model, $\Delta \chi^{2}=11.01, \Delta \mathrm{df}=3, p<0.01$. Therefore, the results suggested that the Equal Direct Effect model was the best-fitting model for the hypothesized moderated mediation model of maltreatment, emotion regulation, and behavior problems, $\chi^{2}(4)=7.97, p=0.09, \quad \mathrm{CFI}=0.96$, RMSEA=0.07 (Fig. 2).

A closer examination of parameter estimates in the Equal Direct Effect model revealed that for both insecure and secure relatedness groups, the direct effects of maltreatment on internalizing and externalizing symptomatology were not significant in the presence of emotion regulation in the model $(B=0.21, S E=0.34, p=0.53$ for maltreatment $\rightarrow$ internalizing symptomatology and $B=-0.36, S E=0.60$, $p=0.55$ for maltreatment $\rightarrow$ externalizing symptomatology). For the insecure relatedness group, there was evidence of significant mediation effects of emotion regulation showing that maltreatment was related to lower levels of emotion regulation $(B=-4.09, S E=1.01, p<0.05)$ which, in turn, was predictive of higher levels of externalizing symptomatology $(B=-0.31, S E=0.06, p<0.05)$ as well as internalizing symptomatology $(B=-0.21, S E=0.04, p<0.05)$. Consistent with our hypothesis, a Sobel's test (1982; MacKinnon et al., 2002) revealed that the relation between child maltreatment and adjustment outcomes was diminished once emotion regulation was added to the regression equation, $Z=3.20, p<0.05$ for internalizing symptomatology, and $Z=3.18, p<0.05$ for externalizing symptomatology. In addition, among children with an insecure pattern of relatedness, boys were lower in emotion regulation $(B=-2.17, S E=1.05, p<0.05)$ and higher in externalizing symptomatology $(B=2.22, S E=.82, p<0.05)$ than girls, but there was no gender difference in terms of internalizing symptomatology $(B=0.13, S E=0.51, p=0.80)$.
In contrast, for the secure relatedness group, the impact of maltreatment on emotion regulation was not significant $(B=0.55, S E=1.13, p=0.62)$. However, similar to the insecure relatedness group, lower levels of emotion regulation were related to higher levels of internalizing $(B=-0.10$, $S E=0.04, p<0.05)$ as well as externalizing symptomatology $(B=-0.42, S E=0.09, p<0.05)$. Among children with a secure pattern of relatedness, boys and girls did not differ with respect to emotion regulation $(B=-1.10, S E=1.12, p=0.32$ ), internalizing $(B=0.22, S E=0.45, p=0.62)$, and externalizing symptomatology $(B=0.89, S E=0.88, p=0.31)$.

\section{A Note about Informant Effects}

Emotion regulation and internalizing and externalizing problems were reported by the same informants. Even though the mean of two informants was used in the analyses, part of the covariance could be explained by rater bias. Therefore, we tested the moderated mediation model using emotion regulation scores from one rater and internalizing and externalizing scores from the other. Similar results were obtained using these data. The relation between maltreatment status and internalizing and externalizing problems was mediated by emotion regulation in the insecure relatedness group $(B=$ -4.36, $S E=1.16, p<0.05$ for maltreatment status $\rightarrow$ emotion regulation, $B=-0.22, S E=0.07, p<0.05$ for emotion regulation $\rightarrow$ externalizing, and $B=-0.19, S E=0.05, p<0.05$ for emotion regulation $\rightarrow$ internalizing problems), but not in the secure relatedness group. The only difference of this model compared to the moderated mediation model with the original data was that in the secure relatedness group, emotion regulation was only related to the level of externalizing problems $(B=-0.19, S E=0.08, p<0.05$ for emotion regulation $\rightarrow$ externalizing, and $B=-0.08, S E=$ $0.05, p=0.12$ for emotion regulation $\rightarrow$ internalizing problems), whereas in the original analysis it was related to both internalizing and externalizing problems. Consistent with the original analysis, maltreatment status was not significantly related to emotion regulation in the secure group $(B=-0.76$, $S E=1.39, p=0.59$ for maltreatment status $\rightarrow$ emotion regulation).

\section{Discussion}

This study sheds light on the processes of the effect of maltreatment on psychopathology. Numerous studies have shown that children who have been maltreated develop maladaptively and are at increased risk for psychopathology (e.g., Manly et al. 2001; Stouthamer-Loeber et al. 2001; Teisl and Cicchetti 2008). We were able to show that this risk for psychopathology is mediated by emotion (dys) regulation, but only for children with an insecure pattern of 
relatedness with their mother. These results were not due to informant effects, since we found similar effects when using emotion regulation data as reported by one informant and psychopathology reported by another.

The development of adequate emotion regulation skills is a salient developmental task (Sroufe 1979, 1995). This development takes place within and is influenced by the child's direct social environment. Parents and other caregivers play an important role in structuring, explaining, and regulating the emotional world of children (Thompson, 2008). When children are being maltreated, their world becomes frightening and unpredictable and often their (maltreating) parents are unavailable to provide the much needed structure and regulation. This is in line with Davies and Cummings' (1994) emotional security hypothesis. This hypothesis is heavily rooted in attachment theory and basically states that family dysfunction may result in emotional insecurity, which in turn, may increase the risk for emotion dysregulation. Being emotionally insecure, i.e., not being able to count on the caregiver's emotional availability, as is characteristic in maltreating families, jeopardizes the capacity to effectively cope with environmental stressors. In a maltreating environment, a child has to be almost constantly aroused and vigilant. These high levels of arousal and vigilance deplete psychological resources that are needed to effectively regulate emotions and behavior. As a result, it becomes increasingly difficult to regulate emotions, in particular in a stressful environment (see also Davies et al. 2006).

The relation between maltreatment and emotion regulation can also be explained from a neurobiological perspective. There are several indications that emotion dysregulation on a behavioral level is related to neurobiological functioning (see Fox 1994). For example, in a study on children in middle childhood, Hessler and Katz (2007) found that children with poorer emotion regulation skills had increased heart rate reactivity to provocative comments. In addition, an impaired ability to regulate distress has been shown to be related to right frontal hemispheric asymmetry (greater right than left activation; Kim and Bell 2006). Maltreatment seems to affect neurobiological structure and functioning (Cicchetti and Tucker 1994; DeBellis 2001) and may therefore affect emotion regulation. For example, alterations in HPA functioning, resulting in an impaired ability to cope with stressors, have often been observed in maltreated children (for a review, see Tarullo and Gunnar 2006). Related to this, the expected correlation between two components of the physiological stress response, salivary alpha amylase and cortisol reactivity, was absent in a group of maltreated 914 year-old children, suggesting asymmetry between these two systems (Gordis et al. 2008). This asymmetry may put the child at risk for impaired emotion regulation skills and heightened levels of psychopathology (Bauer et al. 2002).
Additionally, in an event-related potential (ERP)-study investigating the neural correlates of processing emotional stimuli, Cicchetti and Curtis (2005) showed that maltreated toddlers had greater P260 and $\mathrm{Nc}$ amplitudes in response to looking at angry facial expressions compared to nonmaltreated children, tentatively suggesting that maltreated children would allocate more attention to angry than to happy and neutral faces. Finally, maltreatment also appears to affect hemispheric asymmetry in that maltreated children are more likely to exhibit greater right than left frontal activation (e.g., Curtis and Cicchetti 2007). These findings suggest that maltreated children are likely to have difficulty regulating emotional distress.

In a maltreating environment, different emotion regulation strategies may appear adaptive in the sense that they help maltreated children to cope with their environments (Rogosch et al. 1995). For example, being hypervigilant, or minimizing emotional expressions as a response to a stressor may reduce chances for abuse. However, as we have shown (and consistent with previous research, e.g., Maughan and Cicchetti 2002), in the long run, these emotional responses are maladaptive. Emotion dysregulation places the child at risk for developing internalizing and externalizing types of psychopathology. A vast body of research has identified emotion regulation as an important marker for maladaptation and psychopathology (for an overview, see Gross 1998). It appears to be a key process in the explanation of the effect of maltreatment on later psychopathology (Maughan and Cicchetti 2002; Teisl and Cicchetti 2008), which is also consistent with our own findings.

However, an important addition to the existing literature is our finding that not all maltreated children exhibit impaired emotion regulation skills. We found that a secure pattern of relatedness with their mother plays a moderating role in the effect of being maltreated on the children's ability to regulate their emotions. In addition, our moderated mediation model showed that the effect of maltreatment on internalizing and externalizing problems was only mediated by emotion regulation in the insecure relatedness group. For children with a secure pattern of relatedness with their mother, emotion regulation was not a mediator of this relation because it was unrelated to maltreatment status. When maltreated children indicated that they felt positive and secure in their relationship with their mother and that they were satisfied with the amount of psychological closeness to their mother, their risk for emotion dysregulation declined. Since relationship security only played a role in reducing the risk for psychopathology in maltreated children and not in nonmaltreated children, it can be considered a protective factor - $\mathrm{a}$ factor that buffers or counteracts the effects of risk factors (Werner and Smith 2001).

The buffering effect of relationship security can be explained from a developmental psychopathology perspective (Cicchetti 1984; Rutter and Sroufe 2000). In conceptualizing 
competence, the developmental psychopathology perspective makes use of the construct of resilience. This refers to the fact that some children do well despite facing adversity. Sroufe et al. (2005) view resilience as a developmental process, partly characterized by the development of a secure attachment relationship. Children with a secure attachment relationship with their caregiver are likely to "bounce back" from negative experiences (e.g., Sroufe et al. 1990). This may be because securely attached children are better able to explore the world and feel more competent and confident than children with an insecure attachment (Weinfield et al. 2008). Thus far, most studies have focused on the quality of the relationship between caregivers and infants. The current study shows that similar processes are operating regarding the relationship quality between caregivers and children, measured in middle childhood.

Our finding that 35 of the 111 children who had been maltreated developed a positive pattern of relatedness to their mother, which protected them from maladaptive development, may seem paradoxical in light of the fact that in most cases in our sample (at least 95\%), the perpetrator was the mother. It has to be noted that the pattern of relatedness that we assessed in middle childhood is related but not identical to the attachment relationship assessed in infancy. In middle childhood, we measured aspects of the child's internal working model, or representation of attachment. Although this is based on earlier experiences with the mother, it is also susceptible to change (Waters et al. 2000).

In addition, although attachment representation in middle childhood is based on the early mother-child relationship, other factors may play a role in the formation of a (secure) attachment representation. Congruent with Belsky's (1997a) differential susceptibility hypothesis, certain types of children may be more or less susceptible to environmental influences. Children with a difficult temperament seem to be influenced by parenting to a higher degree than children with an easier temperament (Belsky 1997b; Gilissen et al. 2008b; Van Zeijl et al. 2007). This differential susceptibility pertains to both negative effects of risky environments as well as beneficial effects of supportive environments. In school-aged children with difficult temperaments or personality characteristics (e.g., high fearfulness, high negative emotion, and low adaptability), parenting affects the level of internalizing and externalizing symptomatology, whereas this effect is diminished or absent in children with easier temperaments (reviewed in Gallagher 2002). Based on this theoretical and empirical information, we may hypothesize that maltreated children with easier temperaments or certain personality characteristics (e.g., positive emotionality, high adaptability) are less affected by their abuse experiences and report positive relationships with their mother and, perhaps as a result of this, have developed better emotion regulation skills which accounts for lower levels of internalizing and externalizing problems.

Related to this, maltreated children who reported positive patterns of relatedness may have used defensive processing, a common reaction when individuals are faced with unpleasant events (Kelly and Kahn 1994). These children try to give an impression that all is well (in their relationship with their mother) despite negative histories. Defensive mechanisms operate mainly outside awareness (Bowlby 1980) and function to avoid anxiety and other negative emotions involved in thinking about past experiences. They may be adaptive in the short run, but seem to impair functioning over a longer period of time (e.g., Egeland et al. 1988). More research is needed to test whether reporting a secure pattern of relatedness with their mother is also a protective factor for maltreated children in the long run.

It is also important to draw attention to the composition of our comparison group. Similar to the maltreated group, the comparison group consisted of children from low SES environments and it may be expected that parents in the nonmaltreated group also experienced a fairly large amount of stress. In both the maltreated and nonmaltreated group, the majority of the children had an insecure pattern of relatedness with their mother (69\% and 56\%, respectively). These percentages are considerably higher than the ones found in a more normative sample. Lynch and Cicchetti (1997) showed that in a middle class, suburban sample, only $32 \%$ of the children report having an insecure pattern of relatedness with their mother. Previous research has shown that growing up in a low SES environment is also a risk factor for insecure/disorganized attachment in infancy. Lyons-Ruth et al. (1990) showed that 34\% among children from a low-income environment had a disorganized attachment relationship with their primary caregivers (cf. Cicchetti et al. 2006), compared to $55 \%$ of the children in a maltreated group, whereas in the normal population the percentage of attachment disorganization is only about $15 \%$ (Van IJzendoorn et al. 1999). It is possible that the nature of our comparison group accounted for the fact that we did not find evidence for the expected mediational role of relatedness in the relation between maltreatment and psychopathology. Maltreated children were somewhat less likely than nonmaltreated children to develop a secure pattern of relatedness; however, this effect was quite small $(p=0.06)$ and it did not explain the heightened risk for psychopathology in the maltreated group. It is likely that it would mainly be the high risk of the sample in general and not so much the experience of being maltreated that explains the development of insecure patterns of relatedness, which in turn is related to (internalizing types of) psychopathology.

Despite a large number of favorable study characteristics, such as the careful, prospective assessment of 
maltreatment status, the comparison group being highly demographically similar to the maltreatment group, and observations rated by different counselors in a naturalistic setting, a limitation of this study is its cross-sectional design. Because of this design, the direction of the (mediational) effects has to be interpreted with caution. However, our results are consistent with theory and with previous research. Nevertheless, we recommend replication of these results using a longitudinal research design. In addition, even though we did not find main effects for maltreatment subtype, future studies with a larger sample should explore the possibility that the relation between maltreatment and psychopathology and the effects of relationship quality and emotion regulation might vary as a function of different subtypes of maltreatment.

In conclusion, the current study revealed that emotion regulation is an important mechanism in the development of emotional and behavioral problems. Maltreated children are at risk for developing emotion dysregulation and subsequent psychopathology, but this risk declines when children have a secure pattern of relatedness with their mother. Results from this study may foster interventions aimed at reducing the risk for psychopathology in maltreated children by highlighting the protective effects of developing emotional security with their caregiver.

Open Access This article is distributed under the terms of the Creative Commons Attribution Noncommercial License which permits any noncommercial use, distribution, and reproduction in any medium, provided the original author(s) and source are credited.

\section{References}

Achenbach, T. (1991). Manual for the teacher's report form and 1991 profile. Burlington, VT: University of Vermont, Department of Psychiatry.

Achenbach, T. M. (1995). Empirically based assessment and taxonomy: Applications to clinical research. Psychological Assessment, 7, 261-274.

Warren, S. L., Huston, L., Egeland, B., \& Sroufe, L. A. (1997). Child and adolescent anxiety disorders and early attachment. Journal of the American Academy of Child and Adolescent Psychiatry, 36, 637-644.

Achenbach, T. M., McConaughy, S. H., \& Howell, C. T. (1987). Child/adolescent behavioral and emotional problems: Implications of cross-informant correlations for situational specificity. Psychological Bulletin, 101, 213-232.

Ahnert, L., Gunnar, M. R., Lamb, M. E., \& Barthel, M. (2004). Transition to child care: Associations with infant-mother attachment, infant negative emotion, and cortisol elevations. Child Development, 75, 639-650.

Barnett, D., Manly, J. T., \& Cicchetti, D. (1993). Defining child maltreatment: the interface between policy and research. In D. Cicchetti \& S. L. Toth (Eds.), Child abuse, child development, and social policy, pp. 7-73. Norwood, NJ: Ablex.
Bauer, A. M., Quas, J. A., \& Boyce, W. T. (2002). Associations between physiological reactivity and children's behavior: Advantages of a multisystem approach. Developmental and Behavioral Pediatrics, 23, 102-113.

Beeghly, M., \& Cicchetti, D. (1994). Child maltreatment, attachment, and the self system: Emergence of an internal state lexicon in toddlers at high social risk. Development and Psycho pathology, 62, 5-30.

Belsky, J. (1997a). Variation in susceptibility to environmental influence: An evolutionary argument. Psychological Inquiry, 8, 182-186.

Belsky, J. (1997b). Theory testing, effect-size evaluation, and differential susceptibility to rearing influence: The case of mothering and attachment. Child Development, 64, 598-600.

Block, J., \& Block, J. A. (1980). The California Child Q-Set. Palo Alto, CA: Consulting Psychologists Press.

Bollen, K. A. (1989). Structural equations with latent variables. New York: John Wiley \& Sons.

Bowlby, J. (1980). Attachment and loss: Vol 3. loss: sadness and depression. New York: Basic Books.

Calkins, S. D., \& Fox, N. A. (2002). Self-regulatory processes in early personality development: A multilevel approach to the study of childhood social withdrawal and aggression. Development and Psychopathology, 14, 477-498.

Camras, L. A., Sachs-Alter, E., \& Ribordy, S. C. (1996). Emotion understanding in altreated children: Recognition of facial expressions and integration with other emotional cues. In M. Lewis \& M. W. Sullivan (Eds.), Emotional development in typical children, pp. 203-225. Mahwah, NJ: Erlbaum.

Cicchetti, D. (1984). The emergence of developmental psychopathology. Child Development, 55, 1-7.

Cicchetti, D., \& Curtis, W. J. (2005). An event-related potential study of the processing of affective facial expressions in young children who experienced maltreatment during the first year of life. Development and Psychopathology, 17, 641-677.

Cicchetti, D., \& Manly, J. T. (1990). A personal perspective on conducting research with maltreating families: Problems and solutions. In E. Brody \& I. Sigel (Eds.), Family research journeys: Vol 2. Families at risk, pp. 87-133. Hillsdale, NJ: Erlbaum.

Cicchetti, D., \& Toth, S. L. (2005). Child maltreatment. Annual Review of Clinical Psychology, 1, 409-438.

Cicchetti, D., \& Tucker, D. (1994). Development and self-regulatory structures of the mind. Development and Psychopathology, 6, 533-549.

Cicchetti, D., Ganiban, J., \& Barnett, D. (1991). Contributions from the study of high risk populations to understanding the development of emotion regulation. In J. Garber \& K.A. Dodge (Eds.), The development of emotion regulation and dysregulation, pp. 15-48. New York: Cambridge University Press.

Cicchetti, D., Toth, S. L., \& Lynch, M. L. (1995). Bowlby's dream comes full circle: The application of attachment theory to risk and psychopathology. In T. H. Ollendick \& R. J. Prinz (Eds.), Advances in Clinical Child Psychology, Vol. 17, pp. 1-75. New York: Plenum Press.

Cicchetti, D., Toth, S. L., \& Manly, J. T. (2003). Maternal Maltreatment Classification Interview. Rochester, NY: Unpublished measure.

Cicchetti, D., Rogosch, F. A., \& Toth, S. L. (2006). Fostering secure attachment in infants in maltreating families through preventive interventions. Development and Psychopathology, 18, 623-650.

Cicchetti, D., Rogosch, F.A., Gunnar, M.R., \& Toth, S.L. (2009). The differential impacts of early abuse on internalizing problems and diurnal cortisol activity in school-aged children. Child Development.

Connell, J. P., \& Wellborn, J. G. (1991). Competence, autonomy and relatedness: A motivational analysis of self-system processes. In M. Gunnar \& L. A. Sroufe (Eds.), Minnesota Symposium on Child Psychology, Vol. 22, pp. 43-77. Hillsdale, NJ: Erlbaum. 
Curtis, W. J., \& Cicchetti, D. (2007). Emotion and resilience: A multilevel investigation of hemispheric electroencephalogram asymmetry and emotion regulation in maltreated and nonmaltreated children. Development and Psychopathology, 19, 811-840.

Cyr, C.A., Euser, E.M., Bakermans-Kranenburg, M.J., \& Van IJzendoorn, M.H. (2009). Attachment insecurity and disorganisation in maltreating and high-risk families: A series of metaanalyses. Development and Psychopathology (in press).

Davies, P. T., \& Cummings, E. M. (1994). Marital conflict and child adjustment: An emotional security hypothesis. Psychological Bulletin, 116, 387-411.

Davies, P. T., Winter, M. A., \& Cicchetti, D. (2006). The implications of emotional security theory for understanding and treating childhood psychopathology. Development and Psychopathology, 18, 707-735.

DeBellis, M. D. (2001). Developmental traumatology: The psychobiological development of maltreated children and its implications for research, treatment, and policy. Development and Psychopathology, 13, 539-564.

DeKleyen, M., \& Greenberg, M. T. (2008). Attachment and psychopathology in childhood. In J. Cassidy \& P. R. Shaver (Eds.), Handbook of attachment: Theory, research, and clinical applications, pp. 637-665. New York: Guilford.

Egeland, B., Jacobvitz, D., \& Sroufe, L. A. (1988). Breaking the cycle of abuse. Child Development, 59, 1080-1088.

Fox, N. A. (1994). Dynamic cerebral processes underlying emotion regulation. In: N. A. Fox (Ed.), The development of emotion regulation: Biological and behavioral considerations. Monographs of the Society for Research in Child Development, 59, 152-166.

Gallagher, K. C. (2002). Does child temperament moderate the influence of parenting on adjustment? Developmental Review, 22, 623-643.

Gilissen, R., Bakermans-Kranenburg, M. J., Van IJzendoorn, M. H., \& Linting, M. (2008). Electrodermal reactivity during the Trier Social Stress Test for children: Interaction between the serotonin transporter polymorphism and children's attachment representation. Developmental Psychobiology, 50, 615-625.

Gilissen, R., Bakermans-Kranenburg, M. J., Van IJzendoorn, M. H., \& Van der Veer, R. (2008). Parent-child relationship, temperament, and physiological reactions to fear-inducing film clips: Further evidence for differential susceptibility. Journal of Experimental Child Psychology, 99, 182-195.

Gordis, E. B., Granger, D. A., Susman, E. J., \& Trickett, P. K. (2008). Salivary alpha amylase-cortisol asymmetry in maltreated youth. Hormones and Behavior, 53, 96-103.

Grietens, H., Onghena, P., Prinzie, P., Gadeyne, E., Van Assche, V., Ghesquière, P., et al. (2004). Comparison of mothers', fathers', and teachers' reports on problem behavior in 5- to 6-year-old children. Journal of Psychopathology and Behavioral Assessment, 26, 137-146.

Gross, J. J. (1998). The emerging field of emotion regulation: An integrative review. Review of General Psychology, 2, 271-299.

Hessler, D. M., \& Katz, L. F. (2007). Children's emotion regulation: Self-report and physiological response to peer provocation. Developmental Psychology, 43, 27-38.

Hill, A. L., Degnan, K. A., Calkins, S. D., \& Keane, S. P. (2006). Profiles of externalizing behavior problems for boys and girls across preschool: The roles of emotion regulation and inattention. Developmental Psychology, 42, 913-928.

Hollingshead, A. F. (1975). Four factor index of social status. Yale University: Unpublished manuscript.

Ivanova, M. Y., Achenbach, T. M., Dumenci, L., Almqvist, F., Weintraub, S., Bilenberg, N., et al. (2007). Testing the 8-syndrome structure of the child behavior checklist in 30 societies. Journal of Clinical Child and Adolescent Psychology, 36, 405-417.
Kelly, A. E., \& Kahn, J. H. (1994). Effects of suppression on personal intrusive thoughts. Journal of Personality and Social Psychology, 66, 998-1006.

Kerns, K. A. (2008). Attachment in middle childhood. In J. Cassidy \& P. R. Shaver (Eds.), Handbook of attachment: Theory, research, and clinical applications, pp. 366-382. New York: Guilford.

Kerns, K. A., Tomich, P. L., Aspelmeier, J. E., \& Contreras, J. M. (2000). Attachment-based assessments of parent-child relationships in middle childhood. Developmental Psychology, 36, 614-626.

Kerns, K. A., Abraham, M. M., Schlegelmilch, A., \& Morgan, T. A. (2007). Mother-child attachment in later middle childhood: Assessment approaches and associations with mood and emotion regulation. Attachment and Human Development, 9, 33-53.

Kim, K. J., \& Bell, M. A. (2006). Frontal EEG asymmetry and regulation during childhood. Annals of the New York Academy of Sciences, 1094, 308-312.

Luthar, S. S., Cicchetti, D., \& Becker, B. (2000). The construct of resilience: A critical evaluation and guideline for future work. Child Development, 71, 543-562.

Lynch, M., \& Cicchetti, D. (1991). Patterns of relatedness in maltreated and nonmaltreated children: Connections among multiple representational models. Development and Psychopathology, 3, 207-226.

Lynch, M., \& Cicchetti, D. (1997). Children's relationships with adults and peers: An examination of elementary and junior high school students. Journal of School Psychology, 35, 81-99.

Lyons-Ruth, K., \& Jacobvitz, D. (2008). Attachment disorganization: Genetic factors, parenting contexts, and developmental transformation from infancy to adulthood. In J. Cassidy \& P. R. Shaver (Eds.), Handbook of attachment: Theory, research, and clinical applications, pp. 666-697. New York: Guilford Press.

Lyons-Ruth, K., Connell, D. B., Grunebaum, H. U., \& Botein, S. (1990). Infants at social risks: Maternal depression and family support services as mediators of infant development and security of attachment. Child Development, 61, 85-98.

MacKinnon, D. P., Lockwood, C. M., Hoffman, J. M., West, S. G., \& Sheets, V. (2002). A comparison of methods to test mediation and other intervening variable effects. Psychological Methods, 7, 83-104.

MacKinnon, D. P., Fairchild, A. J., \& Fritz, M. S. (2007). Mediation analysis. Annual Review of Psychology, 58, 593-614.

Manly, J. T., Kim, J. E., Rogosch, F. A., \& Cicchetti, D. (2001). Dimensions of child maltreatment and children's adjustment: Contributions of developmental timing and subtype. Development and Psychopathology, 13, 759-782.

Maughan, A., \& Cicchetti, D. (2002). Impact of child maltreatment and interadult violence on children's emotion regulation abilities and socioemotional adjustment. Child Development, 73, 1525-1542.

Rogosch, F. A., Cicchetti, D., Shields, A. M., \& Toth, S. L. (1995). Parenting dysfunction in child maltreatment. In M. H. Bornstein (Ed.), Handbook of parenting: Vol. 4. Applied and practical considerations of parenting, pp. 127-159. Hillsdale, NJ: Erlbaum.

Rutter, M., \& Sroufe, L. A. (2000). Developmental psychopathology: Concepts and challenges. Development and Psychopathology, 12, 265-296.

Salzinger, S., Rosario, M., \& Feldman, R. S. (2007). Physical child abuse and adolescent violent delinquency: The mediating and moderating roles of personal relationships. Child Maltreatment, $12,208-219$.

Sedlack, A. J., \& Broadhurst, D. D. (1996). The Third National Incidence Study of Child Abuse and Neglect (NIS-3) Final Report. Washington, DC: US Dept of Health and Human Services.

Shields, A., \& Cicchetti, D. (1997). Emotion regulation among school-age children: The development and validation of a new criterion Q-sort scale. Developmental Psychology, 33, 906-916.

Shields, A., \& Cicchetti, D. (2001). Parental maltreatment and emotion dysregulation as risk factors for bullying and victimiza- 
tion in middle childhood. Journal of Clinical Child Psychology, 30, 349-363.

Sobel, M. E. (1982). Asymptotic confidence intervals for indirect effects in structural equations models. In S. Leinhart (Ed.), Sociological methodology, pp. 290-312. San Francisco: Jossey-Bass.

Sroufe, L. A. (1979). Coherence of individual development: Early care, attachment, and subsequent developmental issues. American Psychologist, 34, 834-841.

Sroufe, L. A. (1995). Emotional development: The organization of emotional life in the early years. New York: Cambridge University Press.

Sroufe, L.A., Egeland, B., \& Kreutzer, T. (1990). The fate of early experience following developmental change: Longitudinal approaches to individual adaptation in childhood. Child Development, 61, 1363-1373

Sroufe, L. A., Egeland, B., Carlson, E. A., \& Collins, W. A. (2005). The development of the person: The Minnesota study of risk and adaptation from birth to adulthood. New York: Guilford Press.

Stouthamer-Loeber, M., Loeber, R., Homisch, D. L., \& Wei, E. (2001). Maltreatment of boys and the development of disruptive and delinquent behavior. Development and Psychopathology, 13, 941-955.

Suveg, C., \& Zeman, J. (2004). Emotion regulation in children with anxiety disorders. Journal of Clinical Child and Adolescent Psychology, 33, 750-759.

Tarullo, A. R., \& Gunnar, M. R. (2006). Child maltreatment and the developing HPA axis. Hormones and Behavior, 50, 632-639.

Teisl, M., \& Cicchetti, D. (2008). Physical abuse, cognitive and emotional processes, and aggressive/disruptive behavior problems. Social Development, 17, 1-23.

Thompson, R. A. (2008). Early attachment and later development: Familiar questions, new answers. In J. Cassidy \& P. R. Shaver
(Eds.), Handbook of attachment: Theory, research, and clinical applications, pp. 348-365. New York: Guilford Press.

Toth, S. L., \& Cicchetti, D. (1996). Patterns of relatedness, depressive symptomatology, and perceived competence in maltreated children. Journal of Consulting and Clinical Psychology, 64, 32-41.

Toth, S. L., Manly, J. T., \& Cicchetti, D. (1992). Child maltreatment and vulnerability to depression. Development and Psychopathology, 4, $97-112$.

Van IJzendoorn, M. H., Schuengel, C., \& Bakermans-Kranenburg, M. J. (1999). Disorganized attachment in early childhood: Metaanalysis of precursors, concomitants, and sequelae. Development and Psychopathology, 11, 225-249.

Van Zeijl, J., Mesman, J., Stolk, M. N., Alink, L. R. A., Van IJzendoorn, M. H., Juffer, F., et al. (2007). Differential susceptibility to discipline: The moderating effect of child temperament on the association between maternal discipline and early externalizing problems. Journal of Family Psychology, 21, 626-636.

Waters, E., Merrick, S., Treboux, D., Crowell, J., \& Albersheim, L. (2000). Attachment security in infancy and early adulthood: A twenty-year longitudinal study. Child Development, 17, 684-689.

Weinfield, N. S., Sroufe, L. A., Egeland, B., \& Carlson, E. (2008). Individual differences in infant-caregiver attachment: Conceptual and empirical aspects of security. In J. Cassidy \& P. R. Shaver (Eds.), Handbook of attachment: Theory, research, and clinical applications, pp. 78-101. New York: Guilford Press.

Wellborn, J. G., \& Connell, J. P. (1987). Rochester Assessment Package for Schools. Rochester, NY: University of Rochester.

Werner, E., \& Smith, R. (2001). Journeys from childhood to the midlife: Risk, resilience, and recovery. New York: Cornell University Press. 